\title{
Magnetic and Mechanical Properties of a $6 \%$ Permalloy as Magnetic Head Materials *
}

\author{
By Yoshinobu Sato** and Takeshi Takeyama**
}

\begin{abstract}
The suitability of $6 \% \mathrm{~V}$ Permalloy as magnetic head core materials for use in the digital tape-recording unit of an electronic computer has been investigated with respect to important requirements for the core materials such as effective permeability in a high frequency field, stress-sensitivity in magnetic permeability, wear-resistance and mechanical workability, in comparison with other conventional Permalloys, e.g., $4 \% \mathrm{Mo}$ Permalloy and $4 \% \mathrm{Mo}-5 \% \mathrm{Cu}$ Permalloy. V Permalloy examined has a higher $a c$ magnetic permeability in the high frequency range as well as better $d c$ magnetic properties than the compared alloys, in particular at lower annealing temperature below $1073 \mathrm{~K}$. The stress sensitivity of V Permalloy is very low at all annealing temperatures and exciting frequencies so that the value of permeability under stress remains very high. During the process of rubbing against a magnetic tape at a high speed, thin films are formed on the frictional surface of V Permalloy specimen, and V Permalloy is superior in the wear-resistance to the other Permalloys. V Permalloy has the same order of magnitude of mechanical hardness as the other conventional soft Permalloys and has good workability. From these results, it is thought that $6 \% \mathrm{~V}$ Permalloy is superior to the compared alloys for use as magnetic head material.
\end{abstract}

(Received March 5, 1985)

Keywords: magnetic head material, digital tape-recording, vanadium permalloy, low temperature anneal, permeability, coercivity, stress-sensitivity, wear-resistance

\section{Introduction}

As soft magnetic metallic materials for use in magnetic heads of the tape-recording instruments, high permeability Ni-Fe Permalloy-type alloys containing $\mathrm{Mo}, \mathrm{Cu}$ and $\mathrm{Cr}$ (e.g., Mo Permalloy and Mumetal) and the Sendust alloy in the $\mathrm{Fe}-\mathrm{Al}-\mathrm{Si}$ system are currently used ${ }^{(1)}$. Ni-Fe-Nb alloys of high magnetic permeability and high mechanical hardness have been developed ${ }^{(2)}$ and are used as magnetic head core materials in an audio tape-recorder. In the case of their use as magnetic head core materials in the high density tape-recording unit of an electronic computer, it is indispensable for the core materials to have high effective permeability over a high

* This paper was presented at the 1981 Autumn Meeting of the Japan Institute of Metals. Reported originally in Japanese in J. Japan Inst. Metals, 46 (1982), 1089: The 197th report from the Research Institute of Electric and Magnetic Alloys.

** The Research Institute of Electric and Magnetic Alloys, 2, Yagiyama-Minami, Sendai 982, Japan. frequency range above $100 \mathrm{kHz}$. The core materials are subjected not only to mechanical or thermal stresses in a manufacturing process of the magnetic head but also to stresses due to abrasive contact with a magnetic recording tape during operation. For this reason, in order to secure the uniformity in performance and improvements in resolution in the magnetic head, the core materials should be stress-insensitive in the magnetic properties. They are required to have high wear-resistance against abrasive contact with a magnetic tape sliding at high speed (approximately $6 \mathrm{~m} / \mathrm{s}$ in maximum). Further, the core materials should have good workability to permit cold-rolling down to a sheet thickness of $0.025 \mathrm{~mm}$ and high precision finishing of the magnetic head. From the above considerations, conventional materials such as $4 \%$ Mo Permalloy and $4 \%$ $\mathrm{Mo}-5 \% \mathrm{Cu}$ Permalloy are disadvantageous except as for the workability ${ }^{(3)(4)}$.

It is noted that among various Permalloys, V Permalloy has relatively high electrical resistivity as well as high initial permeability ${ }^{(5)(6)}$. Therefore, we have investigated the 
influence of composition and heat treatment on the effective permeability and stress-sensitivity in thin sheets of $\mathrm{V}$ Permalloy ${ }^{(7)(8)}$. It has been found that $6 \% \mathrm{~V}$ Permalloy possesses excellent properties in regard to the effective permeability over the higher frequency range and the insensitivity to stress with high ductility.

In the present paper, a further investigation has been carried out on magnetic and mechanical properties of $6 \% \mathrm{~V}$ Permalloy for its application to a magnetic head core in the digital tape-recording unit of an electronic computer. Along with the aforesaid requirements, the effective permeability in the high frequency field, the stress effect of permeability and the wear-resistance characteristic in $6 \% \mathrm{~V}$ Permalloy have been examined, and the applicability of the alloy to the magnetic head has been discussed in comparison with the conventional Mo-Cu Permalloy and Mo Permalloy ${ }^{(9)}$.

\section{Experimental}

\section{Specimen preparation}

Electrolytic $\mathrm{Ni}(99.8 \%$ purity), electrolytic $\mathrm{Fe}(99.9 \%$ purity), ferro-V(80.74\%V) and electrolytic $\operatorname{Mn}(99.9 \%$ purity) were used to prepare alloy specimens. The materials weighing $2.3 \mathrm{~kg}$ in total were vacuum-melted by a high frequency induction furnace and cast into an iron mold $47 \mathrm{~mm}$ in inner diameter. The chemical composition of the alloy is shown in Table 1 . The ingot was first heated to $1473 \mathrm{~K}$ and then processed to a slab $7 \mathrm{~mm}$ thick by forging followed by hot-rolling. Second, the slab was annealed in $\mathrm{H}_{2}$ at $1073 \mathrm{~K}$ for $10.8 \mathrm{ks}$ after cleaning by pickling, and coldrolled down to a thickness of about 1-0.35 $\mathrm{mm}$. Finally, three thin strips $0.1,0.05$ and $0.025 \mathrm{~mm}$ thick were prepared by further coldrolling (more than $90 \%$ reduction in area) after intermediate $\mathrm{H}_{2}$ annealing at $1073 \mathrm{~K}$ for $7.2 \mathrm{ks}$. Ring specimens (45 mm o.d., $33 \mathrm{~mm}$ i.d.) with

Table 1 Chemical composition of specimen in mass $\%$.

\begin{tabular}{cccccccc}
\hline \hline $\mathrm{C}$ & $\mathrm{Si}$ & $\mathrm{Mn}$ & $\mathrm{P}$ & $\mathrm{S}$ & $\mathrm{V}$ & $\mathrm{Ni}$ & $\mathrm{Fe}$ \\
\hline 0.005 & 0.25 & 0.49 & 0.002 & 0.002 & 5.80 & 83.01 & Bal. \\
\hline \hline
\end{tabular}

three different thicknesses were stamped out from these thin strips for measurements of the magnetic properties. These ring specimens different in thickness were annealed in a pure $\mathrm{H}_{2}$ atmosphere in the temperature range between 873 and $1373 \mathrm{~K}$ for $3.6-7.2 \mathrm{ks}$ and then furnace cooled (c. $4.17 \times 10^{-2} \mathrm{~K} / \mathrm{s}$ ) to the baking temperature below the order-disorder transformation points (c. $773 \mathrm{~K}$ ), or room temperature. Finally, the baking to obtain the maximum initial permeability was performed on each specimen at $743 \mathrm{~K}$ for $50.4 \mathrm{ks}$ in $\mathrm{H}_{2}$ atmosphere ${ }^{(8)}$. On the other hand, rectangularshaped specimens $10 \times 15 \mathrm{~mm}^{2}$ in dimensions were cut from a $1 \mathrm{~mm}$ thick plate for wear tests, and the shorter thickness sides were used for rubbing tests. The test surface of specimens was polished to a mirror-like surface finish with emery abrasive paper and chromium oxide polishing, and then the specimens were annealed in pure $\mathrm{H}_{2}$ atmosphere at $1173 \mathrm{~K}$ for $7.2 \mathrm{ks}$. Thereafter, they were polished to remove oxide films formed by annealing. In addition, Mo permalloy $(4 \% \mathrm{Mo}, 79 \% \mathrm{Ni}$ and $17 \% \mathrm{Fe}$ ) and $\mathrm{Mo}-\mathrm{Cu}$ Permalloy $(4 \% \mathrm{Mo}, 5 \%$ $\mathrm{Cu}, 77 \% \mathrm{Ni}$ and $14 \% \mathrm{Fe}$ ) were also prepared. They were annealed in pure $\mathrm{H}_{2}$ atmosphere (the same $\mathrm{H}_{2}$ purity as that for V Permalloy) in the temperature range between 873 and $1373 \mathrm{~K}$ for $7.2 \mathrm{ks}$ and then furnace cooled in the temperature range between 873 and $573 \mathrm{~K}$ at an optimum rate of $1.39 \times 10^{-1} \mathrm{~K} / \mathrm{s}$ to achieve the maximum values of initial permeability.

\section{Measurements}

The ring specimens thus prepared were electrically insulated by thin sheets of paper inserted between the laminations and enclosed in protective cases, and coils were uniformly wound around them. The magnetic properties were measured at room temperature. The static magnetic properties were measured by the ballistic method, and the effective permeability $\mu_{\mathrm{e}}(H=0.4 \mathrm{~A} / \mathrm{m})$ over the frequency range $1-300 \mathrm{kHz}$ was determined by the Impedance bridge method. Also, the saturation magnetostriction was measured by using the optical roller method, the electrical resistivity by the four-terminal method using a poten. tiometer, and the hardness by a micro-Vickers 
hardness tester (load $L=0.49 \mathrm{~N}$ ).

The stress-sensitivity in the magnetic properties was measured in terms of the change in $\mu_{\mathrm{e}}$ when the compressional stress $1 \mathrm{MPa}$ was uniformly applied by a load perpendicular to the laminated surface of the heat treated ring specimens.

On the other hand, wear tests were carried out using a tester. The test piece was fixed to a holder and rubbed against a magnetic tape ( $12.7 \mathrm{~mm}$ wide, $570 \mathrm{~mm}$ long) attached to a sponge on the circumferential side of a constant speed rotating wheel. The testing was performed in air at room temperature and humidity $(30-60 \% \mathrm{RH})$ using a $\gamma-\mathrm{Fe}_{2} \mathrm{O}_{3}$ magnetic tape of electronic computers. A contact pressure of $98 \mathrm{kPa}$ and a tape running speed of $3 \mathrm{~m} / \mathrm{s}$ were employed. In order to minimize the influence resulting from the change in the surface condition and to approximate the frictional condition to a virgin surface state, the magnetic tape was replaced with a new one at every run of $5.4 \mathrm{~km}$. The wear was determined from the decrease in length of the test piece using a precision gage.

\section{Results and Discussion}

\section{Magnetic properties}

\section{(1) $d c$ properties}

Figure 1 shows the relation between coercive force $H_{\mathrm{c}}$ (maximum field $H_{\mathrm{m}}=0.8 \mathrm{kA} / \mathrm{m}$ ) and annealing temperature for $6 \% \mathrm{~V}$ Permalloy, $4 \% \mathrm{Mo}-5 \% \mathrm{Cu}$ Permalloy and 4\%Mo Permalloy. To obtain the maximum initial permeability, the specimens were subjected to the respective optimum low temperature heat treatments of the baking at $743 \mathrm{~K}$ (V Permalloy) and the controlled-cooling at the rate of $1.39 \times 10^{-1} \mathrm{~K} / \mathrm{s}$ (Mo-Cu Permalloy and Mo Permalloy) after annealing in the temperature range between 873 and $1373 \mathrm{~K}$. As is seen in the figure, the values $H_{\mathrm{c}}$ of all the Permalloy specimens decrease with increasing annealing temperature. It should be noted that in a lower annealing temperature range $\mathrm{V}$ Permalloy has a very low value of $H_{\mathrm{c}}$. In Table 2 are summarized the values of initial permeability $\mu_{\mathrm{i}}$ $(H=0.08 \mathrm{~A} / \mathrm{m})$ and maximum permeability

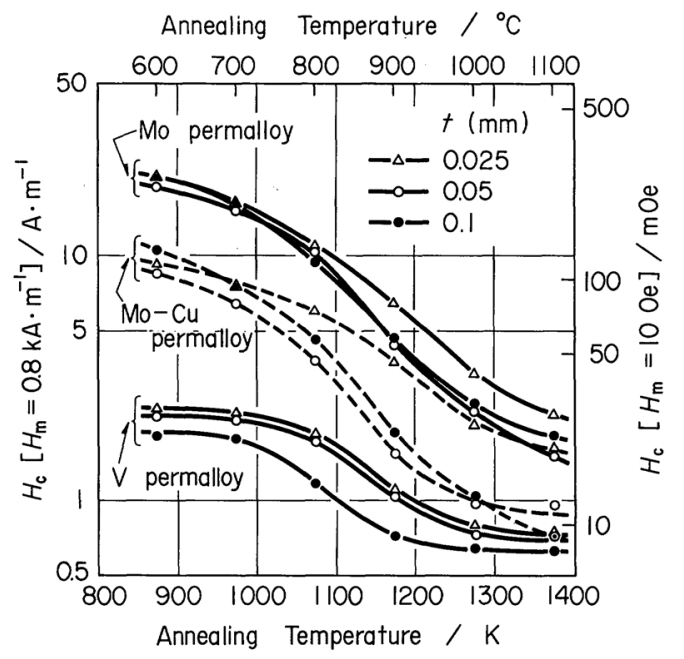

Fig. 1 Coercive force $H_{c}$ curves as a function of annealing temperature for $6 \% \mathrm{~V}$ Permalloy and compared Permalloys, $4 \% \mathrm{Mo}-5 \% \mathrm{Cu}$ Permalloy and $4 \% \mathrm{Mo}$ Permalloy $0.1,0.05$ and $0.025 \mathrm{~mm}$ in sheet thickness.

$\mu_{\mathrm{m}}$, and maximum magnetic induction $B_{\mathrm{m}}$, residual magnetic induction $B_{\mathrm{r}}$ and coercive force $H_{\mathrm{c}}$ in a maximum field of $0.8 \mathrm{kA} / \mathrm{m}$ for $\mathrm{V}$ Permalloy and two other Permalloys $0.05 \mathrm{~mm}$ in thickness annealed at 973 and $1373 \mathrm{~K}$. The values of saturation magnetostriction constant $\lambda_{s}$, electrical resistivity $\rho$ and Vickers hardness Hv were also measured, as shown in the Table 2. It is obvious that V Permalloy annealed at the low temperature is superior in the permeability and $H_{\mathrm{c}}$ to the other Permalloys. The value of $B_{\mathrm{m}}$ in V Permalloy is lower than those of the other alloys. But this will not cause any problem in practical use, so far as the $\gamma-\mathrm{Fe}_{2} \mathrm{O}_{3}$ coated magnetic tape is employed.

\section{(2) ac permeability}

Figure 2 shows the frequency dependence of $\mu_{\mathrm{e}}$ for V Permalloy and the compared alloys with sheet thicknesses of $0.1,0.05$ and 0.025 $\mathrm{mm}$ subjected to the aforementioned optimum low temperature heat treatment after annealing at $973 \mathrm{~K}$. V Permalloy has a higher value of $\mu_{\mathrm{e}}$ than those of the others for all the sheet thicknesses and frequencies measured. This arises not only from the excellent $d c$ magnetic properties but also from the high electrical resistivity as shown in Table 2 . Futher, the variation in $\mu_{\mathrm{e}}$ at measuring frequencies $f$ of 3 


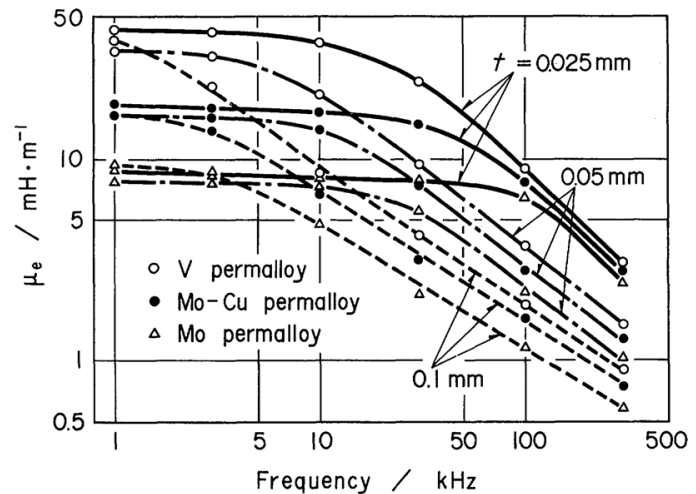

Fig. 2 Frequency dependence of effective permeability for V Permalloy $(\mathrm{O})$ and compared alloys; Mo-Cu Permalloy $(O)$ and Mo Permalloy $(\triangle) 0.1,0.05$ and 0.025 $\mathrm{mm}$ in sheet thickness annealed at $973 \mathrm{~K}$ for 3.6-7.2 ks.

and $100 \mathrm{kHz}$ with annealing temperature is shown by solid curves in Fig. 3 for the three different Permalloys $0.025 \mathrm{~mm}$ thick which were subjected to the optimum low temperature heat treatment after annealing at various temperatures between 873 and $1373 \mathrm{~K}$. In each Permalloy, $\mu_{\mathrm{e}}$ at the lower frequency $3 \mathrm{kHz}$ increases monotonously with annealing temperature, while that at the higher frequency $100 \mathrm{kHz}$ exhibits a peak value at a lower annealing temperature in the range from 973 to 1073 $\mathrm{K}$. The occurrence of this peak seems to be due mainly to the influence of crystal grain size and

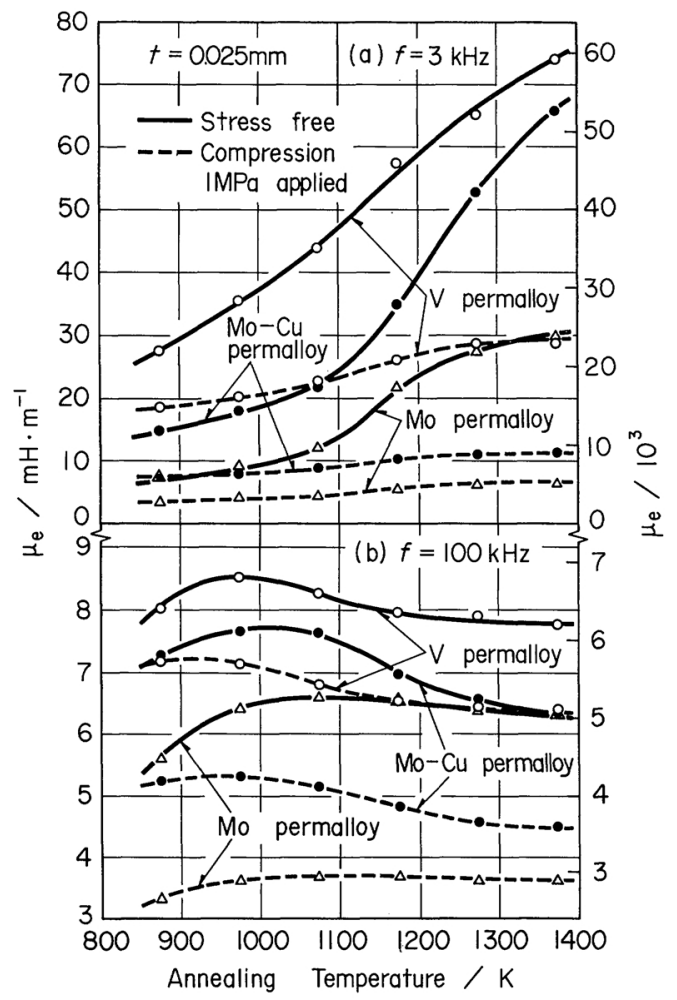

Fig. 3 Variation in effective permeability $\mu_{\mathrm{e}}$ at exciting frequency (a) $3 \mathrm{kHz}$ and (b) $100 \mathrm{kHz}$ with annealing temperature for V Permalloy and compared alloys; Mo$\mathrm{Cu}$ Permalloy and Mo Permalloy $0.025 \mathrm{~mm}$ in sheet thickness. (- : stress free, ----: compressional stress $\sigma=1 \mathrm{MPa}$ applied)

Table 2 Static magnetic properties, saturation magnetostriction, electrical resistivity and Vickers hardness for V Permalloy and two compared Permalloys $0.05 \mathrm{~mm}$ in sheet thickness annealed at $973 \mathrm{~K}$ and $1373 \mathrm{~K}$ for $3.6-7.2 \mathrm{ks}$.

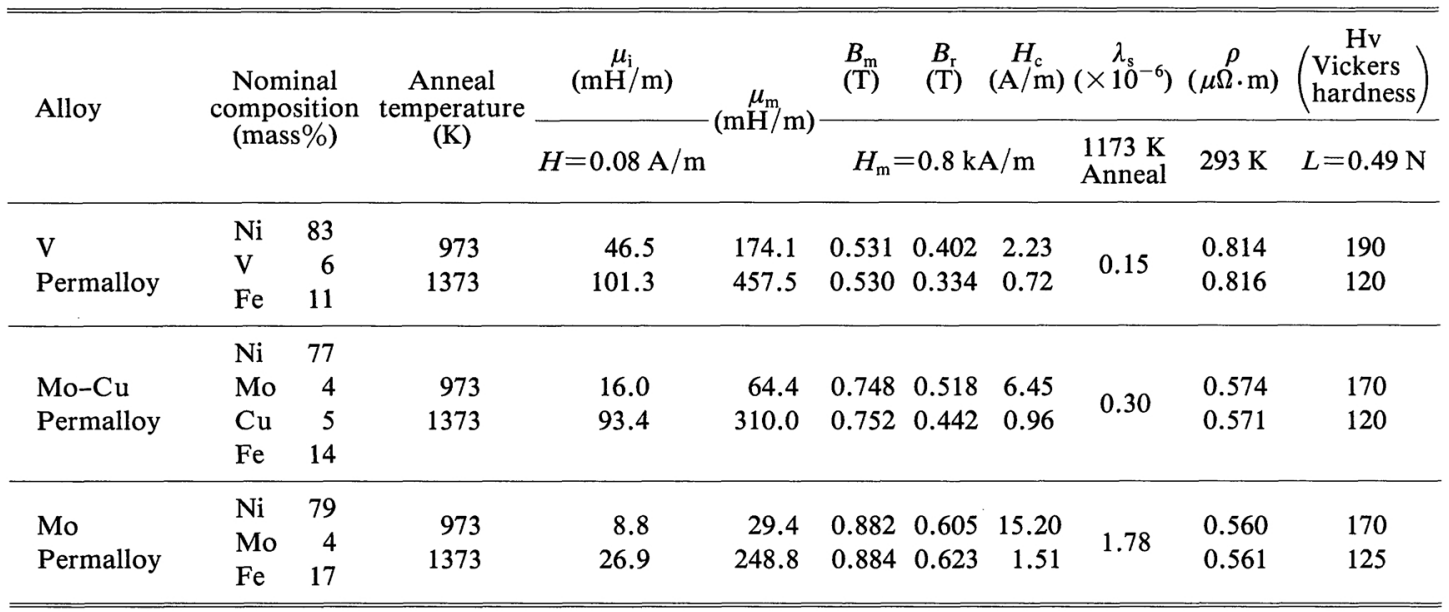


impurity concentration in the alloy on the eddy current loss. Generally speaking, the eddy current loss should depend on the magnetic domain structure and become less as the number of domain walls increases ${ }^{(10)(11)}$. In the case of annealing at low temperature, the alloys have a fine crystal grain (the average cross-sectional area of crystal grains for V Permalloy 0.025 $\mathrm{mm}$ thick sheet annealed at 973 and $1373 \mathrm{~K}$ is $5.28 \times 10^{-5}$ and $2.88 \times 10^{-3} \mathrm{~mm}^{2}$, respectively) and a dense impurity concentration, as shown in Fig. 4. Hence, the fractionization of a magnetic domain would arise from the above situation ${ }^{(12)(13)}$, thus bringing about a less eddy current loss and a larger value of $\mu_{\mathrm{e}}$ in the higher frequency range ${ }^{(14)}$. In addition, as shown in Fig. 3 also, values of $\mu_{\mathrm{e}}$ of V Permalloy are larger than those of the other alloys, in particular at lower annealing temperatures. It is thought that the low coercivity and the high permeability at lower annealing temperatures can be achieved in V Permalloy because the addition of vanadium reduces the detrimental effects of impurities

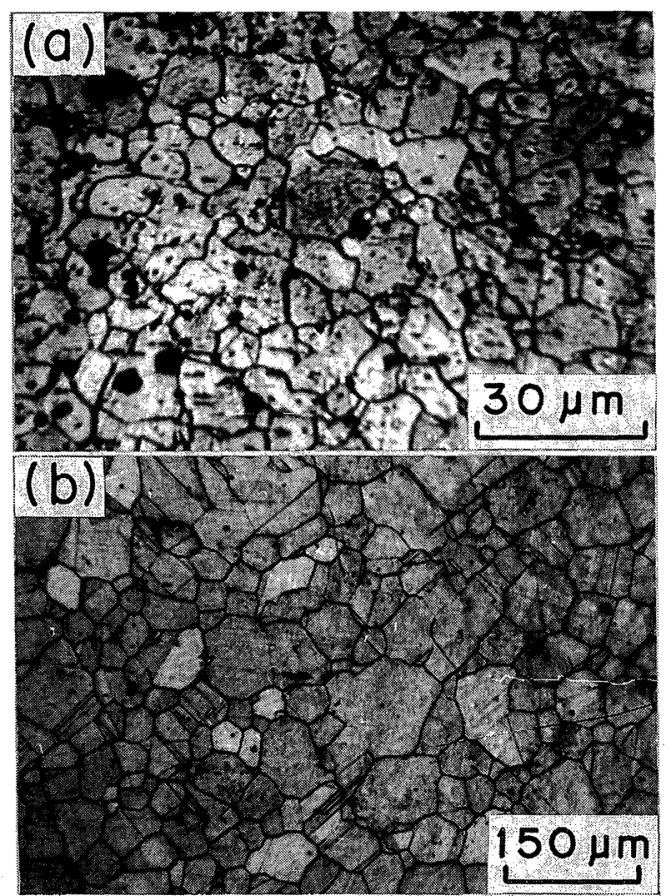

Fig. 4 Microstructures of $\mathrm{V}$ Permalloy $0.025 \mathrm{~mm}$ thick sheet. (a): Annealed at $973 \mathrm{~K}$ for $3.6 \mathrm{ks}$ and (b): annealed at $1373 \mathrm{~K}$ for $3.6 \mathrm{ks}$. such as carbon, nitrogen and oxygen ${ }^{(15)(16)}$. Vanadium is very susceptible to the oxidation and readily forms carbides or nitrides. It might be considered, therefore, that vanadium would have a beneficial influence on improvements in the magnetic properties, e.g., the purification of alloys during melting and the acceleration of grain growth during subsequent recrystallization annealing ${ }^{(17)}$ (the average cross-sectional areas of crystal grains for V Permalloy and Mo Permalloy $0.025 \mathrm{~mm}$ thick sheet annealed at $1073 \mathrm{~K}$ for $3.6 \mathrm{ks}$ are $1.82 \times 10^{-4}$ and $6.72 \times 10^{-5} \mathrm{~mm}^{2}$, respectively).

(3) Change in permeability due to stresses

The variation in $\mu_{\mathrm{e}}$ at $f=3$ and $100 \mathrm{kHz}$ with annealing temperature under the compressional stress $\sigma$ of $1 \mathrm{MPa}$ is indicated by dotted curves in Fig. 3 for the same specimens as those in the case of the aforementioned solid curves. The value of $\mu_{\mathrm{e}}$ decreases under stress in all cases. The rate of decrease, $\Delta \mu_{\mathrm{e}} / \mu_{\mathrm{e}}$, where $\mu_{\mathrm{eo}}$ is the $\mu_{\mathrm{e}}$ value at zero external stress and $\Delta \mu_{\mathrm{e}}$ is the difference between $\mu_{\mathrm{eo}}$ and $\mu_{\mathrm{e}}$ under $\sigma=1 \mathrm{MPa}$, is parallel to the change in $\mu_{\mathrm{eo}}$ with annealing temperature, and is less at lower annealing temperatures. For evaluating the stress-sensitivity, let us use the rate of decrease per unit $\mu_{\mathrm{e}}$, designated as a stress-sensitivity factor $\Delta \mu_{\mathrm{e}} / \mu_{\mathrm{e}}^{2}$, taking into account the difference in the stress-sensitivity characteristic by the magnitude of $\mu_{\mathrm{eo}}$. The variation in the stress-sensitivity factor $\Delta \mu_{\mathrm{e}} / \mu_{\mathrm{co}}^{2}$ with annealing temperature at $f=3$ and $100 \mathrm{kHz}$ is shown in Figs. 5 and 6, respectively, for the Permalloy specimens 0.025 and $0.05 \mathrm{~mm}$ in sheet thickness, subjected to the same heat treatments as the specimens in Figs. 3. As can be seen in Figs. 3, 5 and 6, it is evident that the rate of decrease in V Permalloy is very small and the value of $\mu_{\mathrm{eo}}$ is large at any annealing temperatures. Consequently the stress-sensitivity factor diminishes markedly.

The change in permeability with stress is related to the magnetostriction of material. It may be expected that the magnetostriction is closer to zero and the stress-sensitivity becomes lower, and this results in less deterioration of permeability ${ }^{(18)}$. As indicated in Table 2, the value of $\lambda_{s}$ for V Permalloy is 


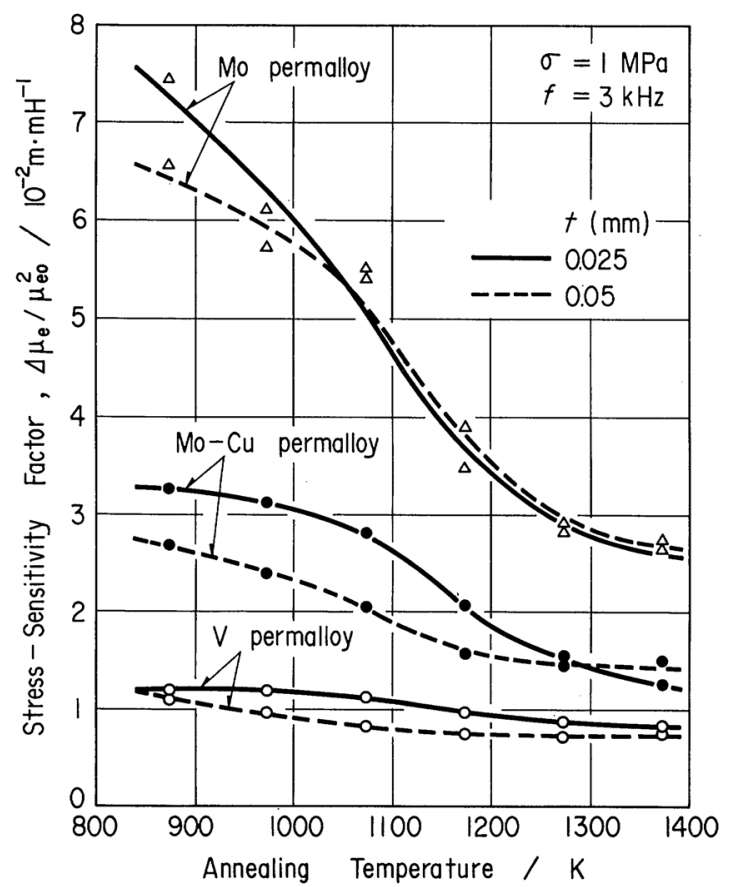

Fig. 5 Variation in stress-sensitivity factor $\left(\Delta \mu_{\mathrm{e}} / \mu_{\mathrm{eo}}^{2}\right)$ with annealing temperature for $\mathrm{V}$ Permalloy and two compared Permalloys $0.025 \mathrm{~mm}$ (solid lines) and $0.05 \mathrm{~mm}$ (dotted lines) in sheet thickness at frequency $3 \mathrm{kHz}$.

quite low. This may be closely connected with the markedly lower stress-sensitivity factor. On the other hand, the magnetostriction in high initial permeability $\mathrm{Ni}-\mathrm{Fe}$ alloys is anisotropic depending on the crystal direction and cannot be reduced to zero simultaneously in all the crystal directions ${ }^{(19)}$. The value of $\lambda_{s}$ for a polycrystalline material is given by such a relation as $\lambda_{s}=\left(2 \lambda_{100}+3 \lambda_{111}\right) / 5$, where $\lambda_{100}$ and $\lambda_{111}$ are the magnetostrictions for the [100] and [111] directions, respectively ${ }^{(18)}$. In the case of alloys of adequate composition, the condition of apparent isotropy and $\lambda_{s} \simeq 0$ may be microscopically realized by refining the crystal grain size and thereby offsetting the magnetostriction among the grains. Further, it is thought that the increase in mechanical hardness of alloys yields deformation resistance and is effective in weakening the sensitivity to stress such as handling damage. Accordingly, V Permalloy which exhibits excellent magnetic properties at lower annealing temperature is suited to the purpose to produce the above condition. It has also been found that $6 \% \mathrm{~V}$ Perm-

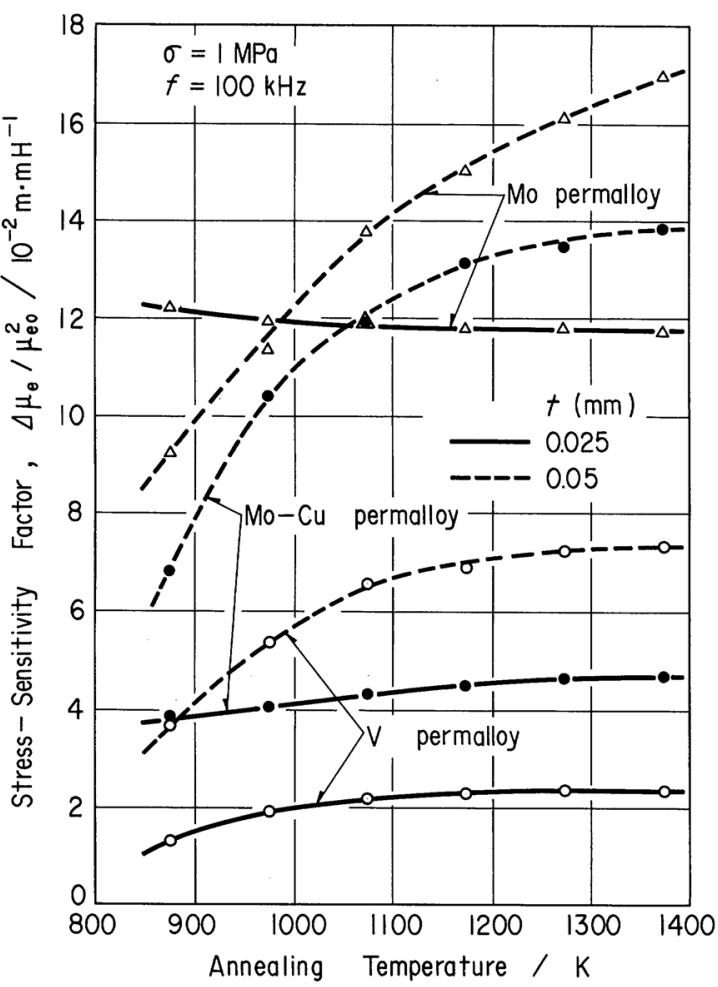

Fig. 6 Variation in stress-sensitivity factor with annealing temperature at frequency $100 \mathrm{kHz}$. (The representation of symbols and lines in the figure is the same as in Fig. 5.)

alloy with $82 \% \mathrm{Ni}$ has a higher value of $\mu_{\mathrm{e}}$ in the higher frequency range than that for the alloy with $83 \% \mathrm{Ni}$, while the degree of deterioration in the magnetic properties with stress is much larger ${ }^{(8)}$. This experimental finding can be attributed to the fact that in the $\mathrm{Ni}-\mathrm{Fe}$ system, the Ni content at which $\lambda=0$ is determined depending on the kind and quantity of the nonmagnetic elements ${ }^{(20)(21)}$. In a study of $6 \% \mathrm{~V}$ Permalloy, it is necessary that the $\mathrm{Ni}$ content should be limited to within $83 \pm 0.2 \%$ to minimize the stress-sensitivity ${ }^{(8)}$.

\section{Mechanical properties}

Recently, Narishige et al. ${ }^{(22)(23)}$ have investigated wears of Permalloy-type alloys by a $\gamma-\mathrm{Fe}_{2} \mathrm{O}_{3}$ magnetic tape. They reported that wears did not vary with mechanical hardness. According to them, some lusterless substance formed on the frictional contact surface of the alloys during rubbing against the magnetic 
tape, had effects which brought about reduction in wear, so that the condition of its formation became an influential factor in the wearresistance characteristic of the alloys. From the experimental results of spectroscopic analysis, they demonstrated also that the substance appeared to be oxides of the alloy constituents, and that in the case of $6 \% \mathrm{~V}$ Permalloy very thin films $20-30 \times 10^{-9} \mathrm{~m}$ in thickness were formed on the rubbed surface of the alloy.

As an example of the wear characteristic of $\mathrm{V}$ Permalloy using a $\gamma-\mathrm{Fe}_{2} \mathrm{O}_{3}$ magnetic tape, the relation between wear quantity and a sliding distance is illustrated in Fig. 7. The wear-resistance characteristic of V Permalloy is by far superior to that of the others despite of the same order of magnitude of mechanical hardness (cf. Table 2). Our result also shows that there is a pronounced difference in wearresistance among the three kinds of Permalloy and the extent of wear has no direct relation with hardness. Further, as shown in Fig. 8, very thin films less than $1 \times 10^{-7} \mathrm{~m}$ thick have been formed on the frictional contact surface of $\mathrm{V}$ Permalloy specimen after the wear testing, while not formed on those of the others. Therefore, the high wear-resistance of

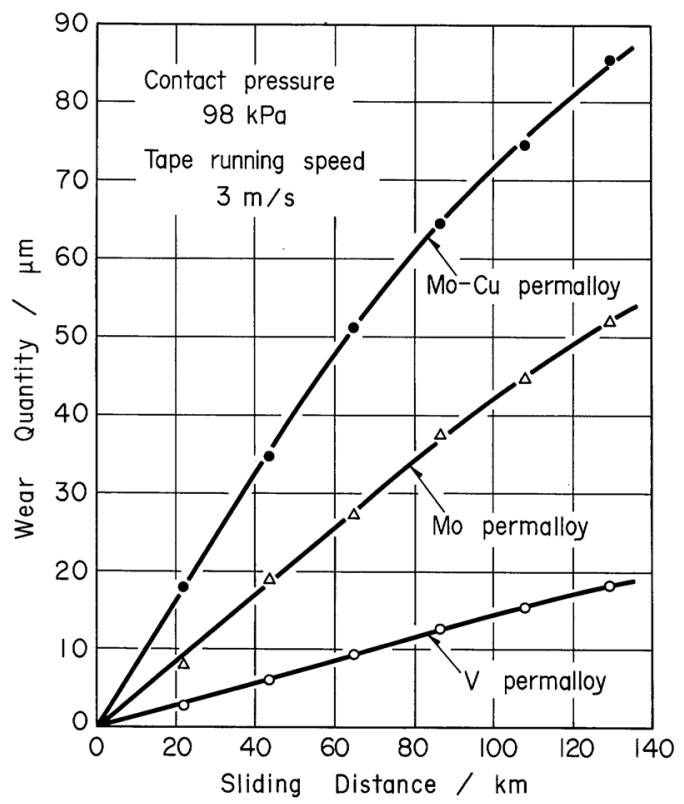

Fig. 7 Wear characteristics of $\mathrm{V}$ Permalloy and compared alloys; Mo-Cu Permalloy and Mo Permalloy, annealed at $1173 \mathrm{~K}$ for $7.2 \mathrm{ks}$.
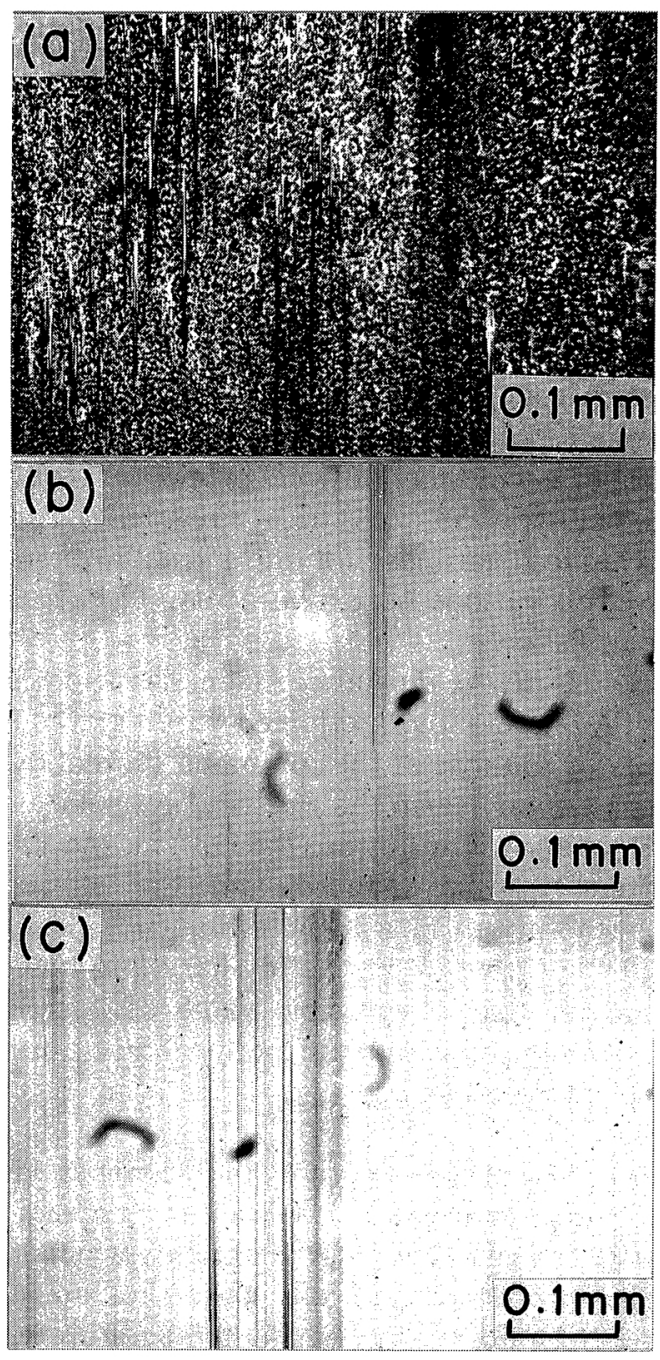

Fig. 8 Optical micrographs of contact surface of V Permalloy (a), Mo Permalloy (b) and Mo-Cu Permalloy (c) specimens after rubbing against $\gamma-\mathrm{Fe}_{2} \mathrm{O}_{3}$ magnetic tape at sliding speed of $3 \mathrm{~m} / \mathrm{s}$ for $32.4 \mathrm{ks}$.

V Permalloy may be explained by wear-resistant effects based on the formation of thin films upon rubbing against the magnetic tape at a high speed.

As indicated in Table 2, there is little difference in mechanical hardness between $\mathrm{V}$ Permalloy and other conventional Permalloys, and V Permalloy has good workability. Therefore, severe cold-rolling to very thin sheets and high-precision finishing by machining and polishing of the alloy can be carried out without difficulty. 


\section{Conclusion}

The suitability of $6 \% \mathrm{~V}$ Permalloy as magnetic head core materials for use in the digital tape-recording unit of an electronic computer was investigated in comparison with other two Permalloys commonly used; $4 \% \mathrm{Mo}$ Permalloy and $4 \% \mathrm{Mo}-5 \% \mathrm{Cu}$ Permalloy. Measurements were carried out on the magnetic properties, stress-sensitivity, wearresistance and other physical properties such as magnetostriction, electrical resistivity and mechanical hardness for the Permalloys subjected to various heat treatments. The results are as follows:

(1) Both the $d c$ and ac magnetic properties of $\mathrm{V}$ Permalloy examined are markedly superior to those of the compared Permalloys. In particular, since the electrical resistivity of V Permalloy is as large as $0.81 \mu \Omega \cdot \mathrm{m}$, the eddy current loss is reduced and the effective permeability $\mu_{\mathrm{e}}$ in a higher frequency field is higher. Further, V Permalloy has a prominent character that a very low value of coercive force and a high value of permeability can be attained by annealing at a temperature below $1073 \mathrm{~K}$.

(2) The stress-sensitivity in $\mu_{\mathrm{e}}$ changes with annealing temperature and exciting frequency. The stress-sensitivity of V Permalloy which has quite a low value of the saturation magnetostriction is very low at any temperature and frequency in spite of the high $\mu_{\mathrm{e}}$ value at zero external stress. Accordingly, $\mathrm{V}$ Permalloy retains a fairly high value of $\mu_{\mathrm{e}}$ even under stress.

(3) During the process of rubbing against the magnetic tape at a high speed, the thin films are formed on the frictional contact surface of V Permalloy specimen, and V Permalloy is superior in the wear-resistance to the conventional Permalloys.

(4) V Permalloy has the mechanical hardness nearly equal to other soft Permalloys, and has good workability which allows us to carry out easily the severe cold-rolling to thin alloy sheets and the high-precision finishing by machining and polishing.

These results mentioned above suggest that $6 \% \mathrm{~V}$ Permalloy excels as a magnetic head material compared with conventional $4 \% \mathrm{Mo}$ Permalloy and 4\%Mo-5\% Cu Permalloy.

\section{Acknowledgments}

The authors would like to thank Dr. Tamotsu Nishina for his guidance and encouragement, and Mr. Toshio Masutani, the former researcher of the Metal Industry Laboratory, for his helpful cooperation in the experiments.

\section{REFERENCES}

(1) Japan Inst. Metals: Kinzoku Deita Bukku (Metals Data Book), Maruzen, Tokyo, (1974), p. 200 (in Japanese).

(2) H. Masumoto, Y. Murakami and M. Hinai: J. Japan Inst. Metals, 35 (1971), 985 (in Japanese); Trans. JIM, 13 (1972), 182.

(3) M. Nishikawa: J. Inst. Electronics Communication Engrs. of Japan, 60 (1977), 1267 (in Japanese).

(4) T. Wakô: J. Mag. Society of Japan, 3 (1979), 13 (in Japanese).

(5) H. Kühlewein: Z. anorg. allgem. Chem., 218 (1934), 603.

(6) U. Hofmann: Z. angew. Phys., 21 (1966), 425.

(7) T. Nishina, Y. Sato and T. Takeyama: Synopses of the 1981 Autumn Meeting of Japan Inst. Metals, p. 447 (in Japanese).

(8) T. Takeyama and Y. Sato: J. Japan Inst. Metals, 48 (1984), 754 (in Japanese).

(9) e.g., R. F. M. Thornley and W. D. Kehr: IEEE Trans. Mag., 7 (1971), 672.

(10) R. H. Pry and C. P. Bean: J. Appl. Phys., 29 (1958), 532.

(11) S. Chikazumi: Kyojiseitai no Butsuri (Physics of Ferromagnetic Materials), Shôkabô, Tokyo, (1959), p. 235 (in Japanese).

(12) S. Chikazumi: Kyojiseitai no Butsuri (Physics of Ferromagnetic Materials), Shôkabô, Tokyo, (1959), p. 162 (in Japanese).

(13) S. Chikazumi: Kyojiseitai no Butsuri (Physics of Ferromagnetic Materials), Shôkabô, Tokyo, (1959), p. 91 (in Japanese).

(14) E. W. Lee: Proc. Instn. Elect. Engrs., 105C (1958), 337.

(15) P. P. Cioffi: Phys. Rev., 39 (1932), 363.

(16) W. E. Messkin and J. M. Margolin: Metals and Alloys, 10 (1939), 26.

(17) N. P. Goss: Iron Age, 171 (1953), 147; ibid., 186.

(18) R. M. Bozorth: Ferromagnetism, D. Van Nostrand, New York, (1951), Chap. 13.

(19) R. M. Bozorth: Revs. Modern Physics, 25 (1953), 42.

(20) F. Pfeifer: Z. Metallk., 57 (1966), 295.

(21) G. Rassman and U. Hofmann: J. Appl. Phys., 39 (1968), 603.

(22) S. Narishige, M. Sato, M. Suwa and S. Tomita: J. Japan Inst. Metals, 42 (1978), 191 (in Japanese).

(23) S. Narishige and M. Sato: J. Japan Inst. Metals, 43 (1979), 1168 (in Japanese). 